\title{
Evaluation Method
}

National Cancer Institute

\section{Source}

National Cancer Institute. Evaluation Method. NCI Thesaurus. Code C81265.

A description of the technique for the appraisal of a subject or object. 